\title{
Effects of $\gamma$-Ray Irradiation on the Fatigue Strength, Thermal Conductivities and Thermal Stabilities of the Glass Fibres/Epoxy Resins Composites
}

\author{
Li-Fang Zheng ${ }^{1} \cdot$ Lu-Ning Wang $^{2} \cdot$ Zhao-Zhong Wang $^{1} \cdot$ Li Wang $^{1}$
}

Received: 19 October 2017 / Revised: 19 November 2017 / Published online: 13 December 2017

(C) The Chinese Society for Metals and Springer-Verlag GmbH Germany, part of Springer Nature 2017

\begin{abstract}
Glass fibres/epoxy resins composites have been performed as ideal materials to make support instruments for high-energy and nuclear physics experiments. The effects of the $\gamma$-ray irradiation on the fatigue strength, thermal conductivities and thermal stabilities of the glass fibres/epoxy resins composites were investigated. And a two-parameter fatigue life model was established to predict the fatigue life of the composites. Results revealed that the $\gamma$-ray irradiation could probably result in the degradation of epoxy resins, but hardly damage to the glass fibres. And the $\gamma$-ray irradiation treatment could significantly affect the fatigue strength of the composites at a low-cycle fatigue stage, but seldom influence at a high-cycle fatigue stage. Furthermore, the fabricated glass fibres/epoxy resins composites after the $\gamma$-ray irradiation still presented excellent fatigue strength, ideal thermal conductivities, remarkable dimensional and thermal stabilities, which can meet the actual requirements of normal operation for supporting instruments under high-energy and nuclear physics experiments.
\end{abstract}

Keywords Epoxy resins composites · Glass fibres $\cdot$ Fatigue strength $\cdot \gamma$-Ray irradiation $\cdot$ Thermal stabilities

\section{Introduction}

Epoxy resins present excellent mechanical strength, remarkable thermal stabilities, low cost and easy processing, etc. [1-6]. Glass fibres/epoxy resins composites have been widely applied as structural components in the fields of aviation and aerospace, microelectronics and transportation, etc., because of their low specific weight, remarkable mechanical strength and heat-resistant, outstanding flame-retardant properties and low thermal conductivity $(\lambda)[7-12]$.

It is worth mentioning that the glass fibres/epoxy resins composites have been performed as ideal materials to make support instruments for high-energy and nuclear physics experiments. The flanges in the second generation of

Available online at http://link.springer.com/journal/40195

Lu-Ning Wang

luning.wang@ustb.edu.cn

1 School of Mechanical Engineering, University of Science and Technology Beijing, Beijing 100083, China

2 School of Materials Science and Engineering, University of Science and Technology Beijing, Beijing 100083, China
Beijing Electron-Positron Collider (BEPCII) are made of glass fibres/epoxy resins composites [13-15] and are exposed to $\gamma$-ray irradiation with the dose of $20 \mathrm{kGy}$. Furthermore, the International Thermonuclear Experimental Reactor (ITER) also regards the glass fibres/epoxy resins composites as ideal support materials for superconducting magnet coils and nuclear fusion reactors $[16,17]$. China is also planning to establish a new-generation electron positron collider with high luminosity (HIEPAF) and much more irradiation dose will be produced, in which the glass fibres/epoxy resins composites will also be used as support material.

However, $\gamma$-ray or neutron irradiation is usually produced in high-energy and nuclear physics experiments, which can significantly influence the physics and chemical properties of the glass fibres/epoxy resins composites [18-22] and finally affect the normal operation of supporting equipments [23-26]. Therefore, it is forwardly needed to systematically investigate the changes of physical and chemical properties (especially for fatigue, thermal conductivities and thermal stabilities) for the glass fibres/ epoxy resins composites before and after $\gamma$-ray or neutron irradiation. Bittner-Rohrhofer et al. [27] reported that the tensile strength of the glass fibres/epoxy resins composites 
in the direction of fibres cloth was decreased by $5 \%$ after neutron radiation, with no changes for fatigue strength. Prokopec et al. [28] reported that the tensile strength of the glass fibres/epoxy resins composites in the direction of fibres cloth was decreased by $5 \%-10 \%$ after neutron radiation, but with no changes for shear strength and dynamic load tensile fatigue curves. Zheng et al. [29] found that the shear strength and the tensile strength were decreased by 10 and $2.4 \%$, respectively, after the combining irradiation of $10 \mathrm{kGy} \gamma$-ray and $4.1 \times 10^{18} \mathrm{~m}^{-2}$ neutron. In addition, Palumbo and co-workers [30] also investigated the effects of irradiation on the ageing and corrosion-resistant properties of the glass fibres/epoxy resins composites.

To the best of our knowledge, the relative researches on the fatigue strength, thermal conductivities and thermal properties of the glass fibres/epoxy resins composites after $\gamma$-ray irradiation are seldom reported. In our present work, according to the $\gamma$-ray irradiation dose of BEPCII, the fabricated glass fibres/epoxy resins composites were exposed to $\gamma$-ray irradiation at different doses of 20, 100 and $200 \mathrm{kGy}$. The corresponding chemical compositions and surface morphologies of the glass fibres/epoxy resins composites were investigated by Fourier transform infrared (FTIR) spectroscopy and scanning electron microscopy (SEM). The effects of the $\gamma$-ray irradiation on the fatigue strength, thermal conductivities and thermal stabilities of the glass fibres/epoxy resins composites were investigated in detail, and a two-parameter fatigue life model was proposed and established to predict the fatigue life of the above composites. This would guide the production and application of such materials in the high-energy physics and nuclear physics fields.

\section{Experimental}

\subsection{Main Materials}

S-glass fibres cloth (mass fraction of alkali is less than $0.5 \%$ ), weaved in 7628 types, was purchased from Nanjing Xingxing Glass Fibre Products Co. Ltd. (Jiangsu, China). 2-Methylimidazole was supplied by Anhui Jinao Chemical Co. Ltd. (Anhui, China). Epoxy resin (E-22) was received from Jiangyin Rongshun Chemical Co. Ltd. (Jiangsu, China), whose chemical structure is

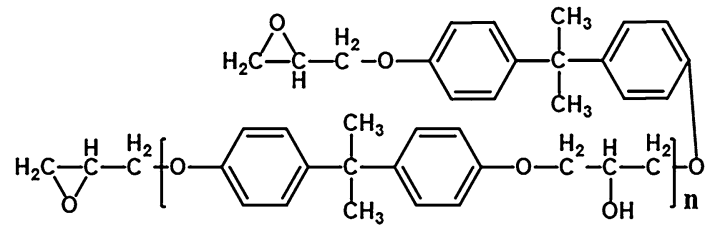

\subsection{Fabrication of Glass Fibres/Epoxy Resins Composites}

The glass fibres/epoxy resins composites were prepared by a resin transfer moulding (RTM) process. The surface of the metal mould was firstly scrubbed by acetone, followed by smearing a release agent. The metal mould filled with glass fibres was heated to the temperature of $50{ }^{\circ} \mathrm{C}$ and kept at $50{ }^{\circ} \mathrm{C}$ for another $12 \mathrm{~h}$. Then, the epoxy resins and 2-methylimidazole were mixed uniformly and injected into the mixing head. Finally, the obtained mixtures were degassed at $50{ }^{\circ} \mathrm{C}$, impregnated into the mould and cured at $90{ }^{\circ} \mathrm{C} / 12 \mathrm{~h}+120{ }^{\circ} \mathrm{C} / 12 \mathrm{~h}$. The ratio of hardener to epoxy resin is $1: 10$. The contents of epoxy resin and glass fibre in the composites are 50 and $50 \%$, respectively, and the void is less than $1.5 \%$.

\subsection{Irradiation and Characterization}

Irradiation experiments were conducted by a ${ }^{60} \mathrm{Co}$-source with a $\gamma$-dose rate of $2 \mathrm{kGy} / \mathrm{h}$ at room temperature (RT) by FJQX multifunction $\gamma$ irradiation facility (Academy of Military Medicine Sciences, China). And the samples were irradiated at doses of 20, 100 and $200 \mathrm{kGy}$, respectively.

FTIR spectra of the samples were obtained on Bruker Tensor II equipment (Bruker Corp., Germany) [31]; SEM morphologies of the samples were analysed by ZEISS ULRTA55 (Carl Zeiss Jena Corp., Germany) [32-34]; thermal gravimetric (TG) analyses of the samples were carried out by SDT Q600 synchronous thermal analyser (TA Instruments Corp., USA) at $10{ }^{\circ} \mathrm{C} / \mathrm{min}$ (nitrogen atmosphere), over the whole range of temperature $\left(25-800{ }^{\circ} \mathrm{C}\right)$.

The tension-tension fatigue tests of the samples were conducted (parallel to the glass fibre layers) using an EA10 electro-hydraulic servo fatigue testing machine (Ji'nan Huaxing Test Equipment Corp., China), according to standard GB/T 16779-2008, and the stress ratio was $R=0.1$ with the frequency of $15 \mathrm{~Hz}$. Herein, 80, 60, 55 and $40 \%$ were chosen as the stress levels $(r)$, respectively. The $\lambda$ value of the samples was measured (perpendicular to the glass fibre layers) using TC3200 thermally conductive coefficient instrument (XIATECH Corp., China) at $60{ }^{\circ} \mathrm{C}$ $[35,36]$, which is much higher than the general usage temperature (below $30{ }^{\circ} \mathrm{C}$ ) to ensure the safe usage. The dimension of the samples was $30 \mathrm{~mm} \times 30 \mathrm{~mm} \times 5 \mathrm{~mm}$. Coefficient of thermal expansion (CTE) value of the samples was carried out (parallel to the glass fibre layers) on DIL 402C thermal dilatometer (Netzsch Corp., Germany) in argon atmosphere with a flow rate of $150 \mathrm{~mL} / \mathrm{min}$. The test temperature was from $\mathrm{RT}$ to $150{ }^{\circ} \mathrm{C}$ with a heating rate 
of $2{ }^{\circ} \mathrm{C} / \mathrm{min}$. The corresponding dimension of the samples was $25 \mathrm{~mm} \times 5 \mathrm{~mm} \times 5 \mathrm{~mm}$.

\section{Results and Discussion}

\subsection{FTIR and SEM Analyses}

FTIR spectra of the glass fibres/epoxy resins composites before and after $\gamma$-ray irradiation are shown in Fig. 1. The absorption bands at 1461,1509 and $1609 \mathrm{~cm}^{-1}$ are ascribed to the $\mathrm{C}=\mathrm{C}$ stretching vibration absorption peaks of benzene ring. And the peaks at 1033 and $1240 \mathrm{~cm}^{-1}$ are corresponded to the $\mathrm{R}-\mathrm{O}$ and $\mathrm{Ar}-\mathrm{O}$ stretching vibration, respectively. All the absorption peaks are weakened with the increasing dose of $\gamma$-ray irradiation. It can be attributed that the $\mathrm{C}=\mathrm{C}, \mathrm{R}-\mathrm{O}$ and $\mathrm{Ar}-\mathrm{O}$ bonds are broken partially or completely under the $\gamma$-ray irradiation $[37,38]$. There is no appearance of new characteristic peaks, revealing no new chemical bonds produced for epoxy resins after the $\gamma$-ray irradiation.

SEM images of tensile-tensile fatigue fractures of the glass fibres/epoxy resins composites are shown in Fig. 2. The $\gamma$-ray irradiation hardly damages to the glass fibres. But for epoxy resins, several debris (orange circles) and gas pores (blue circles) appear (Fig. 2b-d). And the number of debris is also increased with the increasing dose of $\gamma$-ray irradiation, which is probably ascribed to the degradation of epoxy resins [39]. However, the gas pores could not be seen in epoxy resins after $200 \mathrm{kGy}$ irradiation. The reason is that the epoxy resins become debris severely and the gas pores produced in Fig. 2b, c were damaged. Under this circumstance, the interfacial debonding between epoxy matrix and glass fibres is the main damage patterns.

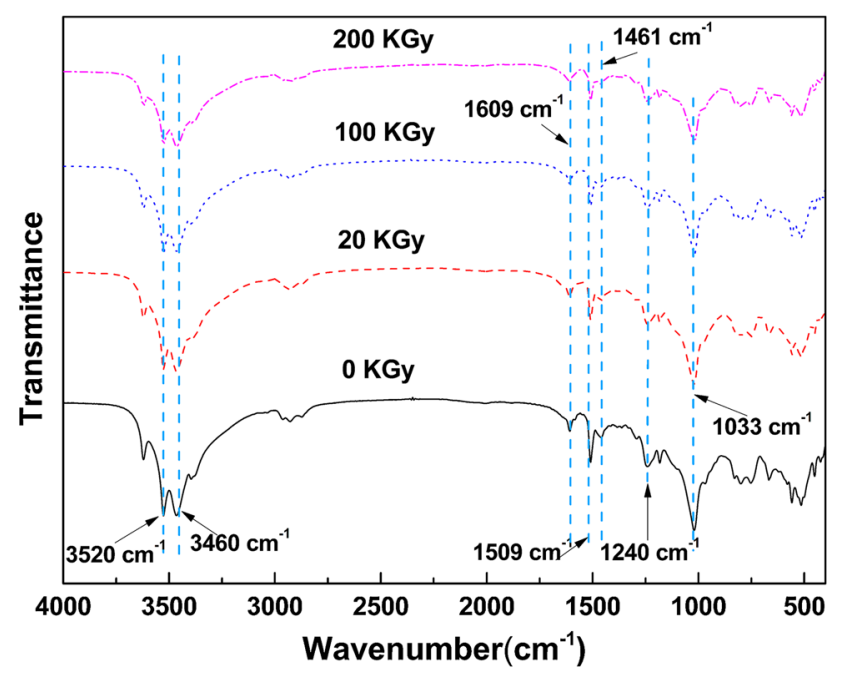

Fig. 1 FTIR spectra of epoxy resins in the glass fibres/epoxy composites before and after $\gamma$-ray irradiation
Meantime, the colour of the glass fibres/epoxy resins composites is also changed from yellowish to brown with the increasing dose of $\gamma$-ray irradiation, probably attributed to combined action of degradation and cross-linking reaction under $\gamma$-ray irradiation [40, 41]. When epoxy resin is subjected to irradiation, the degradation reaction and crosslinking reaction occur simultaneously, which are the most basic reactions that affect the epoxy resin properties. If the degradation reaction is stronger than the cross-linking reaction, the molecular weight of the materials will continue to decrease. If the cross-linking reaction is stronger than the degradation reaction, the new cross-linking polymers will generate.

\subsection{Tensile Fatigue Properties of the Composites}

Results of fatigue test for the glass fibres/epoxy resins composites are listed in Table 1. The mean static tensile strength of the composites before $\gamma$-ray irradiation is 190.6 MPa. With the increasing dose of the $\gamma$-ray irradiation, the corresponding mean static tensile strength gradually decreases to $184.5,183.0$ and $176.1 \mathrm{MPa}$, reduced by $3.22,4.01$ and $7.60 \%$, respectively. On one hand, the $\gamma$-ray irradiation may break the molecular chains of epoxy resins, to decrease the interfacial bonding strength between epoxy matrix and glass fibres. On the other hand, $\gamma$-ray irradiation can weaken the reinforcing effects of the glass fibres.

Based on the mean static tensile strength and the stress ratio $(R=0.1)$, the mean stress $\left(\sigma_{\mathrm{m}}\right)$ and stress strength amplitude $\left(\sigma_{\mathrm{a}}\right)$ are calculated at different $r$ values, and fatigue cycle number $(N)$ is also tested. Figure 3 shows the $S-N$ life curves of the glass fibres/epoxy resins composites under different irradiation doses.

For a given $N$ value, at a low-cycle fatigue stage (fatigue cycle number $N<10^{4}$ ), the maximum stress is gradually decreased with the increasing $\gamma$-ray irradiation dose. Meantime, for a given tensile stress value, the corresponding $N$ is also gradually decreased with the increasing $\gamma$-ray irradiation dose. Results demonstrate that $\gamma$-ray irradiation can significantly affect the fatigue strength of the glass fibres/epoxy resins composites at a low-cycle fatigue stage. However, at a high-cycle fatigue stage $\left(N \geq 10^{4}\right)$, all the $S-N$ curves present the similar changing tendency, indicating that $\gamma$-ray irradiation hardly affects the fatigue strength at a high-cycle fatigue stage.

According to the concept and assumption of fatigue modulus introduced by Hwang and Han [42-44], fatigue cycle number of the glass fibres/epoxy resins composites can be predicted under the strain failure criterion through applying $r$ value by Eq. (1).

$\ln (1-r)=c \ln N-\ln B$. 

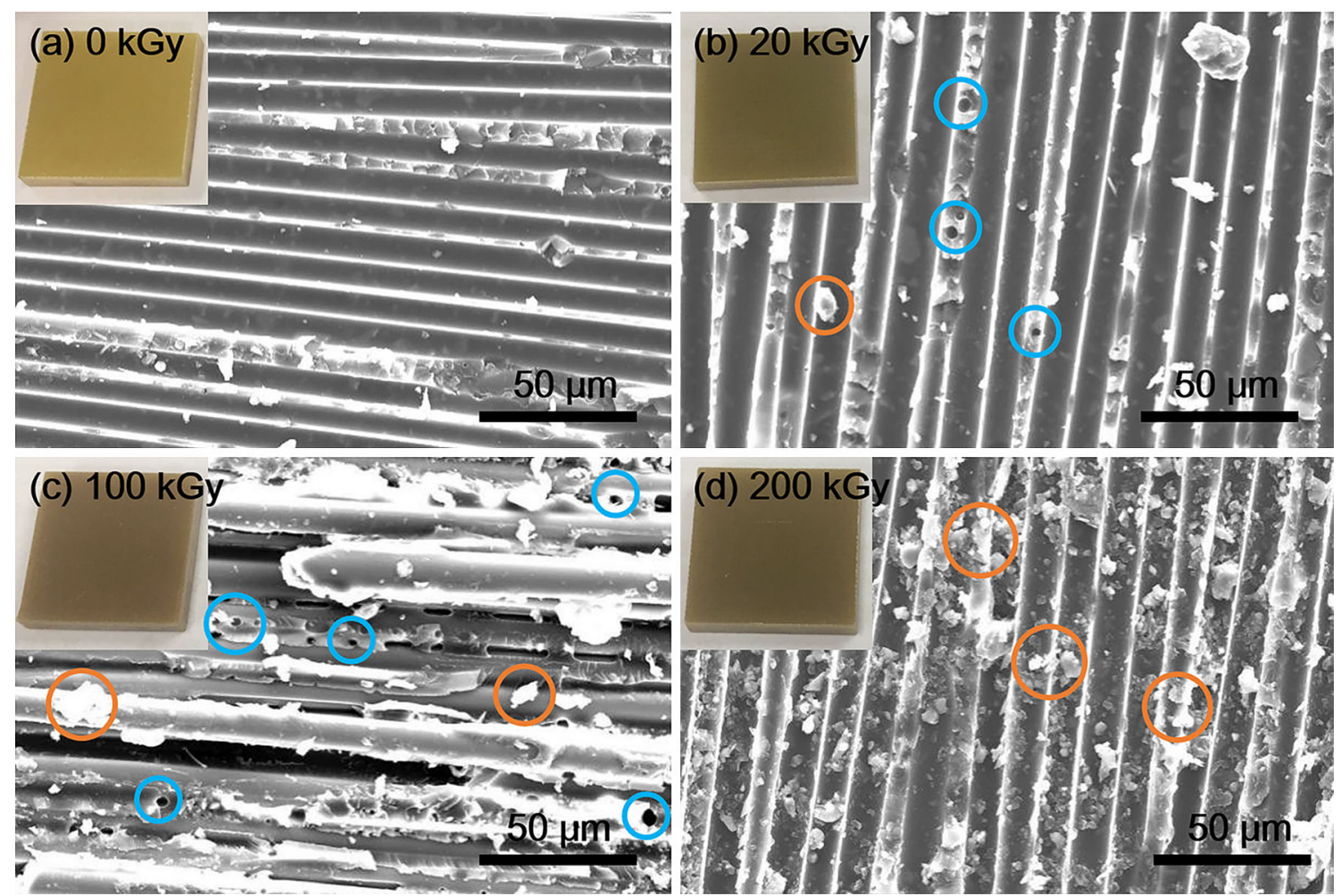

Fig. 2 SEM images of tensile-tensile fatigue fractures of the glass fibres/epoxy resins composites under different $\gamma$-ray irradiation doses: a $0 \mathrm{kGy}$, b $20 \mathrm{kGy}$, c $100 \mathrm{kGy}$, d $200 \mathrm{kGy}$ (gas pores are circled by blue circles; debris of epoxy resin is circled by orange circles). (Color figure online)

Table 1 Results of fatigue test for the glass fibres/epoxy resins composites before and after $\gamma$-ray irradiation

\begin{tabular}{|c|c|c|c|c|c|c|c|}
\hline $\begin{array}{l}\text { Irradiation } \\
\text { dose }(k G y)\end{array}$ & $\begin{array}{l}\text { Mean static tensile } \\
\text { strength }(\mathrm{MPa})\end{array}$ & $\begin{array}{l}\text { Stress level, } \\
r(\%)\end{array}$ & $\begin{array}{l}\text { Mean stress, } \sigma_{\mathrm{m}} \\
(\mathrm{MPa})\end{array}$ & $\begin{array}{l}\text { Stress amplitude, } \\
\sigma_{\mathrm{a}}(\mathrm{MPa})\end{array}$ & $\begin{array}{l}\text { Fatigue cycle number, } \\
N \text { (cycle) }\end{array}$ & $\ln (1-r)$ & $\ln N$ \\
\hline \multirow[t]{4}{*}{0} & \multirow[t]{4}{*}{190.63} & 80 & 83.60 & 68.40 & 526.75 & -1.6094 & 6.2667 \\
\hline & & 60 & 62.70 & 51.30 & 4569 & 0.9163 & 8.4271 \\
\hline & & 55 & 57.48 & 47.03 & 8209 & 0.7985 & 9.0130 \\
\hline & & 40 & 41.80 & 34.20 & 243,162 & 0.5108 & 12.4015 \\
\hline \multirow[t]{4}{*}{20} & \multirow[t]{4}{*}{184.50} & 80 & 81.40 & 66.60 & 954 & -1.6094 & 6.8607 \\
\hline & & 60 & 61.05 & 49.95 & 5852 & -0.9163 & 8.6745 \\
\hline & & 55 & 55.96 & 45.79 & 13,188 & -0.7985 & 9.4871 \\
\hline & & 40 & 40.70 & 33.30 & 353,245 & -0.5108 & 12.7749 \\
\hline \multirow[t]{4}{*}{100} & \multirow[t]{4}{*}{182.99} & 80 & 79.20 & 64.80 & 1091.25 & -1.6094 & 6.9951 \\
\hline & & 60 & 59.40 & 48.60 & 6637 & -0.9163 & 8.8004 \\
\hline & & 55 & 54.45 & 44.55 & 14,973 & -0.7985 & 9.6140 \\
\hline & & 40 & 39.60 & 32.40 & 467,244 & -0.5108 & 13.0546 \\
\hline \multirow[t]{4}{*}{200} & \multirow[t]{4}{*}{176.14} & 80 & 77.44 & 63.36 & 1166 & -1.6094 & 7.0613 \\
\hline & & 60 & 58.08 & 47.52 & 8337 & -0.9163 & 9.0285 \\
\hline & & 55 & 53.24 & 43.56 & 16,970 & -0.7985 & 9.7392 \\
\hline & & 40 & 38.72 & 31.68 & 600,128 & -0.5108 & 13.3049 \\
\hline
\end{tabular}

Equation (1) reflects the tension-tension fatigue test data with minimal error, and the fatigue life of the glass fibres/epoxy resins composites can be predicted with much fewer experiments [45, 46]. Equation (1) is a linear equation between $\ln (1-r)$ and $\ln N$, and the two parameters of $c$ and $\ln B$ are constant and can be determined by calculating the slope and intercept of the line. 


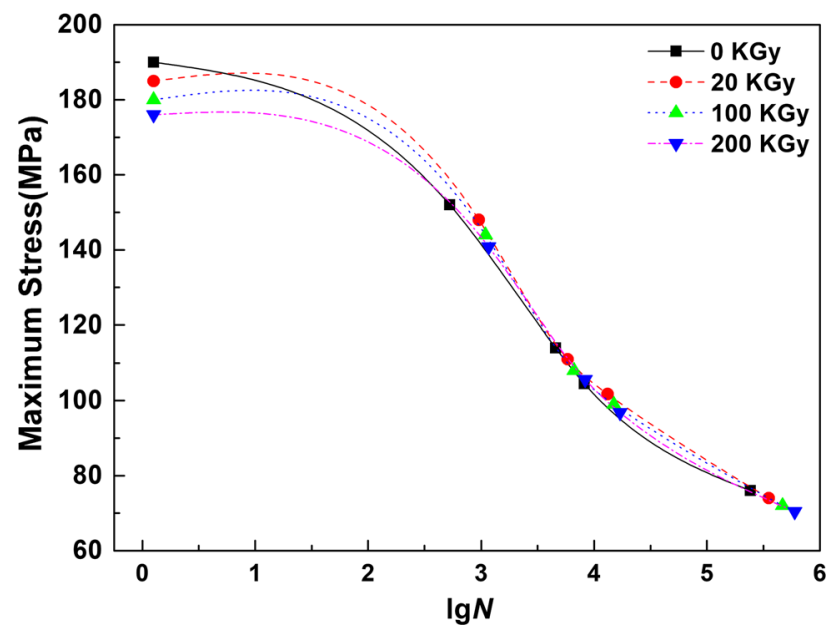

Fig. $3 S-N$ curves of the glass fibres/epoxy composites under different $\gamma$-ray irradiation doses

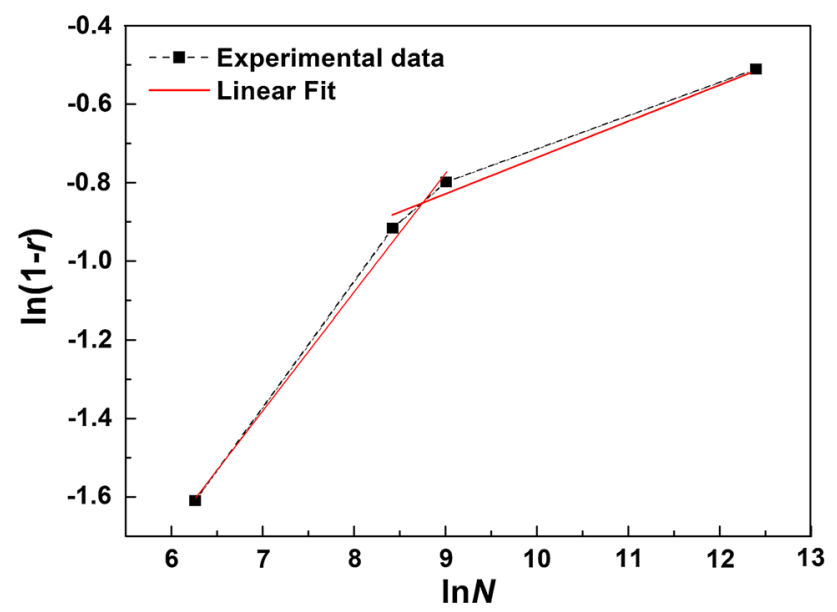

Fig. 4 Piecewise fitting curve of the samples before $\gamma$-ray irradiation

The least squares method is performed to fit the line between $\ln (1-r)$ and $\ln N$ in Table 1 . According to the $S_{-}$ $N$ curves in Fig. 3, the fatigue cycle number at a low-cycle fatigue stage $\left(N<10^{4}\right)$ is different remarkably from that of a high-cycle fatigue stage $\left(N \geq 10^{4}\right)$. Therefore, the fatigue cycle number at different fatigue stages cannot be calculated by the same model and the line must be fitted piecewise. The fitting curve between $\ln (1-r)$ and $\ln N$ of the samples before $\gamma$-ray irradiation is shown in Fig. 4, and the two-parameter fatigue life model of the glass fibres/ epoxy composites with 20, 100 and $200 \mathrm{kGy}$ irradiation dose is obtained and listed in Table 2. The value of $N$ can be estimated by substituting $r$ value into the two-parameter fatigue life model.

The highest cycle number $N$ in the experiment is $6 \times 10^{5}$, and the limit of the fatigue cycle number $N$ of the glass fibres/epoxy resins composites is $5 \times 10^{6}$. According to the established two-parameter fatigue life model, $r$ of the glass fibres/epoxy resins composites at $N=5 \times 10^{6}$ cycles can be calculated, and the fatigue limit $\left(\sigma_{-1}\right)$ can be predicted as $32.08,33.28,33.51$ and $33.33 \mathrm{MPa}$ with the irradiation dose of $0,20,100$ and $200 \mathrm{kGy}$, respectively. The prediction results reveal that there is no obvious change in $\sigma_{-1}$ values before and after $\gamma$-ray irradiation at $N=5 \times 10^{6}$, consistent with the experimental results in Fig. 4 at a high-cycle fatigue stage.

\subsection{Thermal Conductivities of the Composites}

Figure 5 presents the $\lambda$ values of the glass fibres/epoxy resins composites before and after $\gamma$-ray irradiation. The maximum $\lambda$ value of the composites before $\gamma$-ray irradiation is $0.706 \mathrm{~W} / \mathrm{mK}$, which is mainly ascribed to a relatively higher $\lambda$ value of the glass fibres. However, after the $\gamma$-ray irradiation at 20,100, $200 \mathrm{kGy}$, the corresponding $\lambda$ value is slightly decreased to $0.539,0.667$ and $0.695 \mathrm{~W} /$ $\mathrm{mK}$, respectively. The reason is probably attributed that the $\gamma$-ray irradiation may break the molecular chains of epoxy resins, resulting in the interfacial debonding strength between epoxy matrix and glass fibres, finally to introduce some defects (gas or cavities) inner the composites.
Table 2 Two-parameter fatigue life model of the glass fibres/ epoxy composites with 20,100 and $200 \mathrm{kGy}$ irradiation doses

\begin{tabular}{lllll}
\hline Irradiation dose $(\mathrm{kGy})$ & $c_{1}$ & $B_{1}$ & Two-parameter fatigue life model & $N$ (Cycle) \\
\hline 0 & 0.30220 & 32.98622335 & $N=[32.98622335(1-r)]^{1 / 0.30220}$ & $<10^{4}$ \\
20 & 0.32103 & 44.06782833 & $N=[44.06782833(1-r)]^{1 / 0.32103}$ & \\
100 & 0.32197 & 46.29898321 & $N=[46.29898321(1-r)]^{1 / 0.32197}$ & \\
200 & 0.31341 & 44.98998907 & $N=[44.98998907(1-r)]^{1 / 0.31341}$ & \\
\hline Irradiation dose (kGy) & $c_{2}$ & $B_{2}$ & Two-parameter fatigue life model & $N($ Cycle) \\
\hline 0 & 0.09025 & 5.153107857 & $N=[5.153107857(1-r)]^{1 / 0.09025}$ & $\geq 10^{4}$ \\
20 & 0.09362 & 5.513998276 & $N=[5.513998276(1-r)]^{1 / 0.09362}$ & \\
100 & 0.09587 & 5.740291540 & $N=[5.740291540(1-r)]^{1 / 0.09587}$ & \\
200 & 0.09801 & 5.987476273 & $N=[5.987476273(1-r)]^{1 / 0.09801}$ &
\end{tabular}




\subsection{Thermal Properties of the Composites}

\subsubsection{Dimensional Stabilities of the Composites}

CTE can be calculated using Eq. (2)

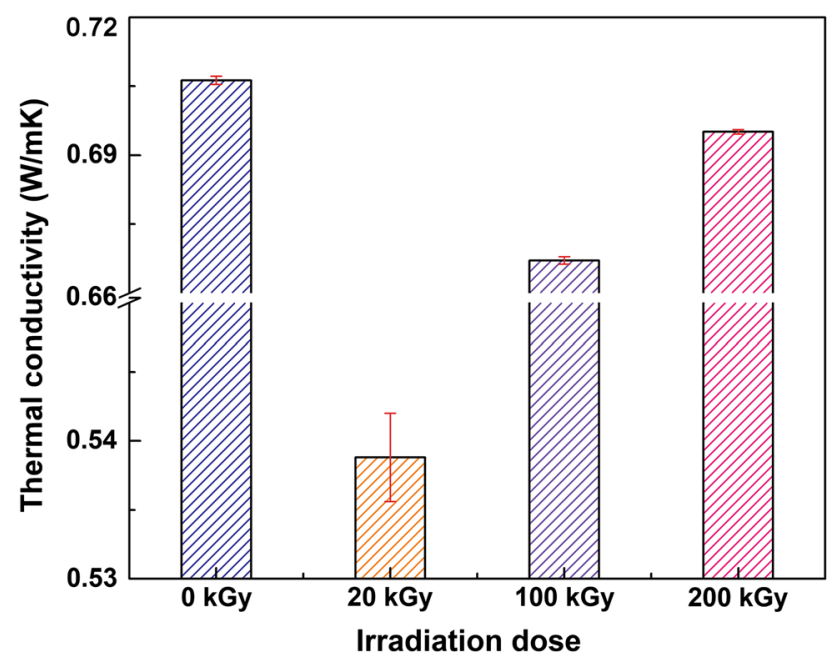

Fig. 5 Thermal conductivities of the glass fibres/epoxy composites before and after $\gamma$-ray irradiation
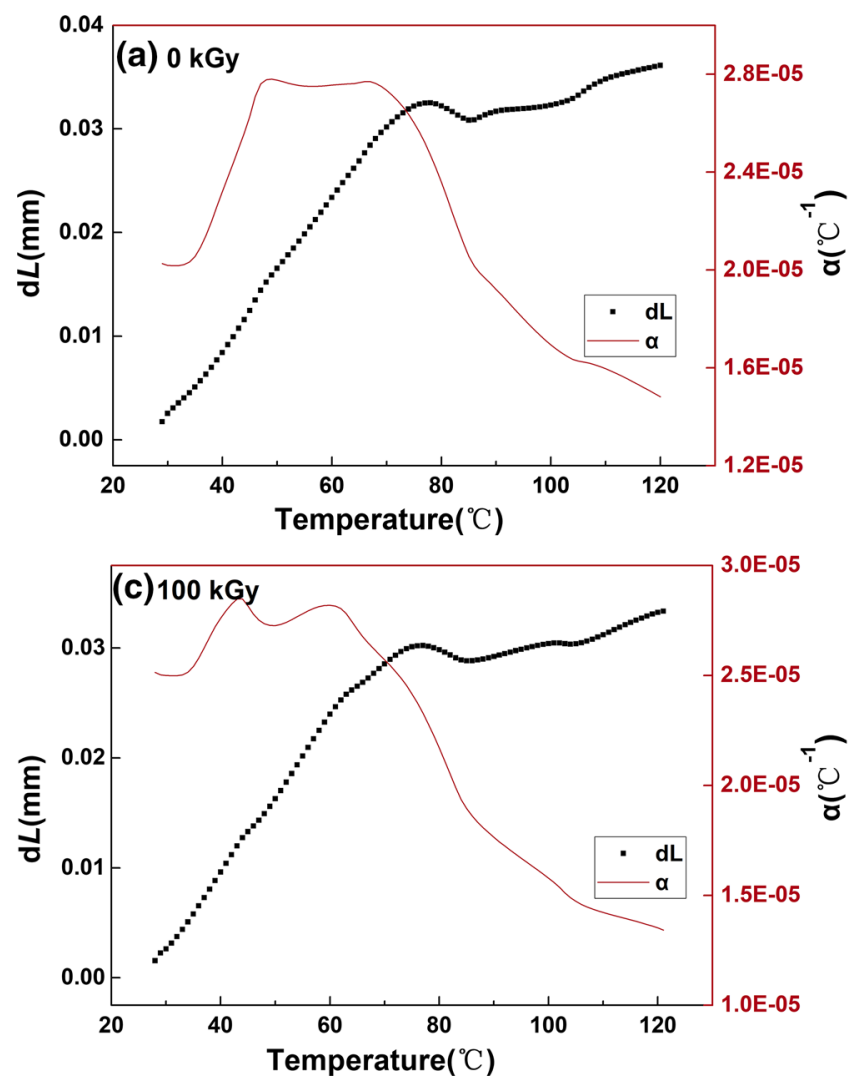

$\alpha_{\mathrm{t}}=\frac{1}{L} \frac{\mathrm{d} L}{\mathrm{~d} T}$

where $\alpha$ is $\mathrm{CTE},{ }^{\circ} \mathrm{C}, \alpha_{\mathrm{t}}$ is the coefficients of linear thermal expansion (CLTE) in a certain temperature; $L$ is length of the samples, $\mathrm{mm}$; and $T$ is experimental temperature, ${ }^{\circ} \mathrm{C}$.

Figure 6 shows the corresponding CTE values of the glass fibres/epoxy resins composites before and after $\gamma$-ray irradiation. It can be seen that the glass fibres/epoxy resins composites before $\gamma$ irradiation expanded linearly at RT$60{ }^{\circ} \mathrm{C}$. According to Eq. (2) and Fig. 6a, the CLTE value of the glass fibres/epoxy resins composites before $\gamma$-ray irradiation is calculated as $2.79 \times 10^{-5} /{ }^{\circ} \mathrm{C}$. And after the $\gamma$-ray irradiation at 20, 100 and $200 \mathrm{kGy}$, the corresponding CLTE value of the composites is decreased slightly to $2.59 \times 10^{-5} /{ }^{\circ} \mathrm{C}, \quad 2.59 \times 10^{-5} /{ }^{\circ} \mathrm{C}$ and $2.61 \times 10^{-5} /{ }^{\circ} \mathrm{C}$, respectively. It reveals that the glass fibres/epoxy resins composites still present excellent heat resistance deformation performance at the range of $25-120{ }^{\circ} \mathrm{C}$ after the $\gamma$ ray irradiation, revealing the excellent dimensional stabilities.
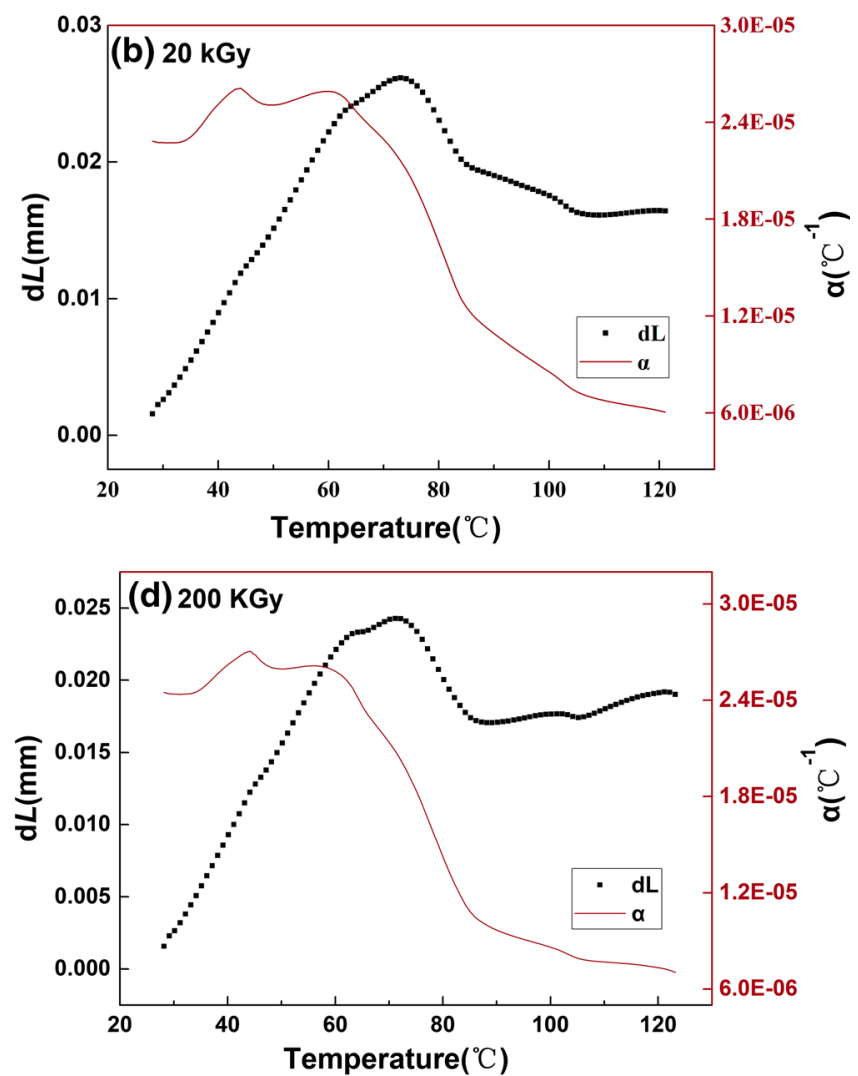

Fig. 6 Variation of elongation and CTE with respect to the temperature under different $\gamma$-ray irradiation doses: a 0 kGy, b $20 \mathrm{kGy}$, c $100 \mathrm{kGy}$, d $200 \mathrm{kGy}$ 


\subsubsection{Thermal Stabilities of the Composites}

In Fig. 7, there are three peaks in all of the differential thermal gravity (DTG) curves of the four groups of specimens, and thermal degradation can be divided into three stages. In the first stage, the temperature is $200-310{ }^{\circ} \mathrm{C}$. The weight loss of the composites is around $10 \%$, which is caused by the loss of dopant and small molecules. In the second stage, major weight loss is about $15 \%$ at $310-420{ }^{\circ} \mathrm{C}$ and the rate of degradation rose, which caused the degradation of epoxy resin. In the last stage, the weight loss is about $5 \%$ at $420-600{ }^{\circ} \mathrm{C}$. Small molecules of epoxy resin polymer produced in the second stage degraded further $[47,48]$. Because the mass fraction of glass fibre in the composites is about $50 \%$ in this research, and glass fibre cannot decompose in the range of the experimental temperature, the maximum percentages of the samples before and after irradiation are 30-40\% in Fig. 7, which are all in the normal range, 50\%. The composites present similar thermal weight loss tendency and the maximum weight loss temperature after the $\gamma$-ray irradiation, revealing outstanding thermal stabilities. Additionally, all DSC curves show distinct trough at $300{ }^{\circ} \mathrm{C}$. And the area of the exothermic peak of the composites before and after $\gamma$-ray irradiation is different, decreased from 172.6 to 142.7 , 119.0 and $71.2 \mathrm{~J} / \mathrm{g}$ at $20,100,200 \mathrm{kGy}$, respectively. It can be explained by the incompletely cured epoxy resin, which undergoes further curing reaction under $\gamma$-ray irradiation. The greater the irradiation dose, the more the curing reaction, which results in a gradual decrease in the curing peak. Additionally, the glass transition temperature $\left(T_{\mathrm{g}}\right)$ of the composites can be obtained from the DSC curves. It can be seen from Fig. 7 that $T_{\mathrm{g}}$ of the composites before and after $\gamma$-ray irradiation at 20,100 and $200 \mathrm{kGy}$ is about $62.3,60.7,59.3$ and $60.5{ }^{\circ} \mathrm{C}$, respectively. It reveals that $\gamma$ ray irradiation does not affect $T_{\mathrm{g}}$ of the composites remarkably.

\section{Conclusion}

FTIR analysis revealed that the $\gamma$-ray irradiation could probably result in the degradation of epoxy resins, but hardly damage to the glass fibres. After $\gamma$-ray irradiation,
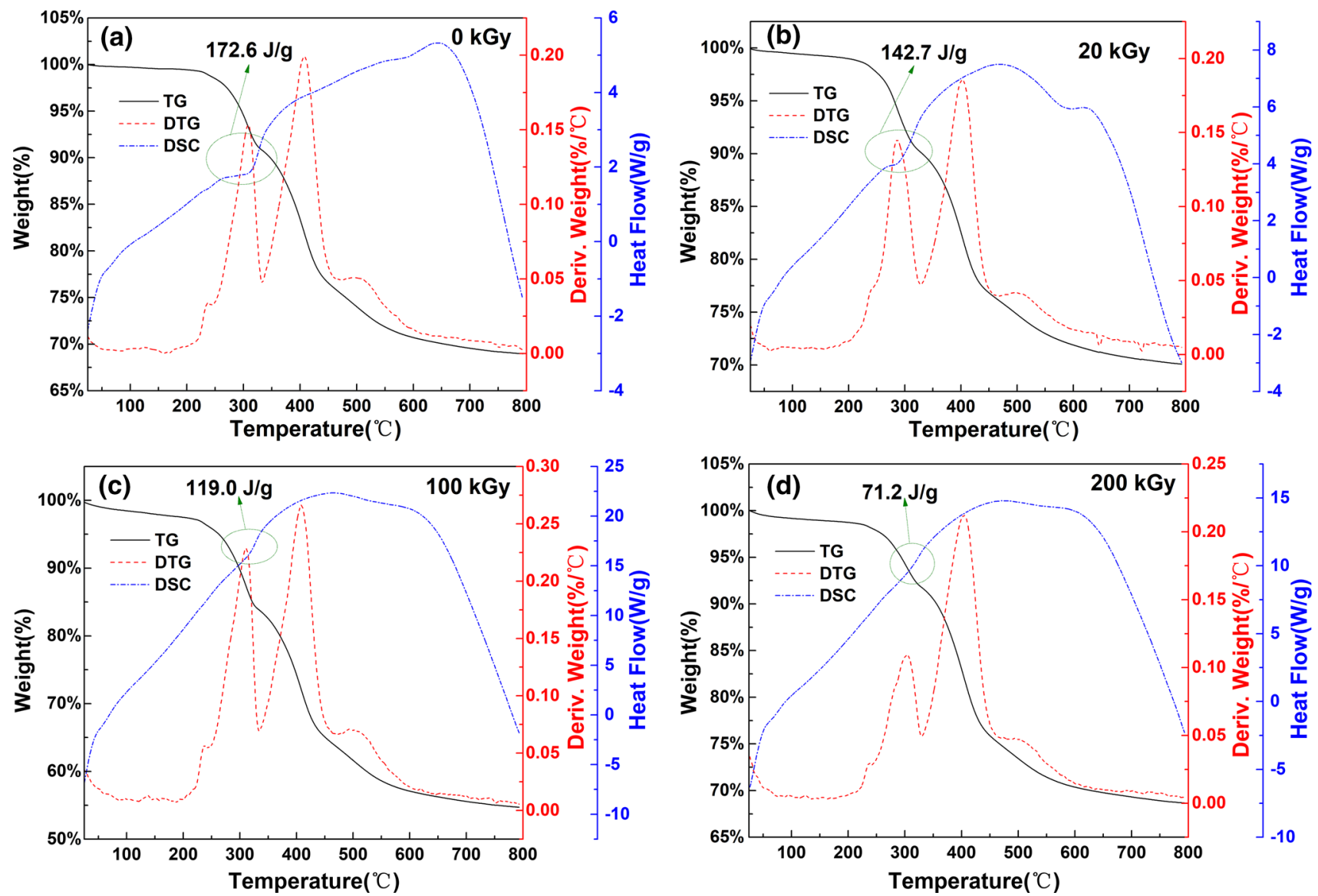

Fig. 7 TG, DTG and DSC curves of the glass fibres/epoxy composites under different $\gamma$-ray irradiation doses: a 0 kGy, b 20 kGy, c $100 \mathrm{kGy}$ and d $200 \mathrm{kGy}$ 
the interfacial debonding between epoxy matrix and glass fibres is the main damage patterns, and the colour of the composites was also changed from yellowish to brown with the increasing dose of $\gamma$-ray irradiation. In addition, the corresponding mean static tensile strength of the composites was also gradually decreased from 190.6 to 184.5 , 183.0 and $176.1 \mathrm{MPa}$, reduced by $3.22,4.01$ and $7.60 \%$, respectively. The $\gamma$-ray irradiation could significantly affect the fatigue strength of the composites at a low-cycle fatigue stage, but seldom influence at a high-cycle fatigue stage. Moreover, the glass fibres/epoxy resins composites still presented excellent thermal conductivities, outstanding dimensional and thermal stabilities after the $\gamma$-ray irradiation. This would guide the production and application of such materials in the high-energy physics and nuclear physics fields.

Acknowledgements This work was financially supported by the National Natural Science Foundation of China (No. 51605025), the Major Program of National Key Research and Development Program of China (2016YFC0802905), the Fundamental Research Funds for the Central Universities (FRF-GF-17-B19), the BEPC great reconstruction project and the Knowledge Innovation Fund of the Chinese Academy of Sciences, U-603 and U-34 (IHEP).

\section{References}

[1] X. Shen, Z. Wang, Y. Wu, X. Liu, Y.B. He, J.K. Kim, Nano Lett. 16, 3585 (2016)

[2] A.T. Sunny, M. Mozetic, G. Primc, S. Mathew, S. Thomas, Compos. Sci. Technol. 146, 34 (2017)

[3] Q. Feng, J. Yang, Y. Liu, J. Mater. Sci. Technol. 30, 90 (2014)

[4] H.B. Gu, C. Ma, C.B. Liang, X.D. Meng, J.W. Gu, Z.H. Guo, J. Mater. Chem. C 5, 4275 (2017)

[5] C.B. Liang, P. Song, H.B. Gu, C. Ma, Y.Q. Guo, H.Y. Zhang, Compos. A 102, 126 (2017)

[6] J.W. Gu, Q.Y. Zhang, H.C. Li, Y.S. Tang, J. Kong, J. Dang, Polym. Plast. Technol. Eng. 46, 1129 (2007)

[7] Y. Hao, F. Liu, E.H. Han, J. Mater. Sci. Technol. 28, 1077 (2012)

[8] M.S. Islam, L. Tong, Compos. A Appl. Sci. Manuf. 84, 196 (2016)

[9] Z.X. Wu, J.W. Li, C.J. Huang, R.J. Huang, L.F. Li, J. Nucl. Mater. 441, 67 (2013)

[10] X. Zhang, Y. Xue, H. Zhang, J. Mater. Sci. Technol. 31, 159 (2014)

[11] J. Garcia-Espinel, D. Castro-Fresno, P.P. Gayo, F. BallesterMuñoz, Mater. Des. 66, 46 (2015)

[12] J.F. Ding, Q. Zeng, J. Mater. Sci. Technol. 30, 590 (2014)

[13] C. Zhang, Chin. Phys. C 33, 60 (2009)

[14] G. Xu, Q. Qin, C.H. Yu, High Energy Phys. Nucl. 30, 60 (2006)

[15] K. Wen, High Energy Phys. Nucl. 29, 611 (2005)

[16] G. Federici, P. Andrew, P. Barabaschi, J. Brooks, R. Doermer, A. Geier, J. Nucl. Mater. 313, 11 (2003)
[17] J.J. Xin, F. Chao, Y.T. Song, J. Wei, C.J. Huang, P. Libeyre, IEEE Trans. Appl. Supercond. 27, 1 (2017)

[18] C.M. Manjunatha, A.C. Taylor, A.J. Kinloch, J. Mater. Sci. 44, 342 (2009)

[19] M. Hayashi, Y. Nakata, F. Mishima, Y. Akiyama, S. Nishijima, Phys. Proc. 58, 236 (2014)

[20] J.W. Li, Z.X. Wu, C.J. Huang, L.F. Li, Fusion Eng. Des. 89 , 3112 (2014)

[21] K. Humer, P. Rosenkranz, H.W. Weber, P.E. Fabian, J.A. Rice, J. Nucl. Mater. 283, 973 (2000)

[22] A. Idesaki, T. Nakamoto, M. Yoshida, L. Masami, K. Sasaki, M. Sugano, Fusion Eng. Des. 112, 418 (2016)

[23] Y.Q. Wang, K.C. Kou, L.H. Zhuo, G.L. Wu, Polym. Compos. 38, 523 (2017)

[24] X.Z. Sui, W.Y. Zhou, L.N. Dong, Z.J. Wang, P. Wu, J. Zuo, J. Electron. Mater. 45, 5974 (2016)

[25] K. Bittner-Rohrhofer, K. Humer, H.W. Weber, Cryogenics 42, 265 (2002)

[26] X. Shen, X.Y. Lin, J.J. Jia, Z.Y. Wang, Z.G. Li, J.K. Kim, Carbon 80, 235 (2014)

[27] K. Bittner-Rohrhofer, K. Humer, H. Fillunger, J. Nucl. Mater. 329, 1083 (2004)

[28] R. Prokopec, K. Humer, R.K. Maix, H.W. Weber, P.E. Fabian, N.A. Munshi, J. Phys. Conf. Ser. 43, 739 (2006)

[29] L.F. Zheng, Z.M. Qiao, X.H. Xu, L. Wang, Fusion Eng. Des. 117, 24 (2017)

[30] D. Palumbo, R.D. Finis, P.G. Demelio, U. Galietti, Compos. B 103, 60 (2016)

[31] J.W. Gu, W.C. Dong, Y.S. Tang, Y.Q. Guo, L. Tang, J. Kong, J. Mater. Chem. C 5, 6929 (2017)

[32] Y. Jia, K. Li, S. Zhang, J. Mater. Sci. Technol. 30, 1202 (2014)

[33] J.W. Gu, C.B. Liang, X.M. Zhao, B. Gan, H. Qiu, Y.Q. Guo, Compos. Sci. Technol. 139, 83 (2017)

[34] B. Wielage, D. Richter, H. Mucha, J. Mater. Sci. Technol. 24, 953 (2008)

[35] X.H. Li, L.B. Shao, N. Song, L.Y. Shi, P. Ding, Compos. A 88, 305 (2016)

[36] J.W. Gu, X.T. Yang, Z.Y. Lv, N. Li, C.B. Liang, Q.Y. Zhang, Int. J. Heat Mass Transf. 92, 15 (2016)

[37] N. Longieras, M. Sebban, P. Palmas, A. Rivaton, J.L. Gardette, Polym. Degrad. Stabil. 92, 2190 (2007)

[38] J.Z. Sun, Radiat. Phys. Chem. 60, 445 (2001)

[39] M. Garg, S. Sharma, R. Mehta, J. Mater. Sci. 51, 8562 (2016)

[40] S.N. Li, A.J. Gu, J. Xue, G.Z. Liang, L. Yuan, Appl. Surf. Sci. 265, 519 (2013)

[41] Y.H. Zhang, Y.D. Huang, L. Liu, L. Wu, Mater. Sci. Technol. 18, 648 (2010)

[42] W. Hwang, K.S. Han, J. Compos. Mater. 20, 125 (1986)

[43] A. Aeran, S.C. Siriwardane, O. Mikkelsen, Int. J. Fatigue 103, 327 (2017)

[44] H.L. Huang, Q.C. He, J. Mater. Sci. Technol. 20, 6 (2004)

[45] M. Shahverdi, A.P. Vassilopoulos, T. Keller, Compos. A 43, 1689 (2012)

[46] J.A. Glud, J.M. Dulieu-Barton, O.T. Thomsen, L.C.T. Overgaard, Compos. A 95, 359 (2017)

[47] J.S. Chen, C.K. Ober, M.D. Poliks, Y. Zhang, U. Wiesner, C. Cohen, Polymer 45, 1939 (2004)

[48] J.W. Gu, J. Dang, Y.L. Wu, C. Xie, Y. Han, Polym. Plast. Technol. 51, 1198 (2012) 